\title{
BMJ Open Methods for a longitudinal cohort of refugee children in a regional community in Australia
}

\author{
Karen Zwi, ${ }^{1}$ Santuri Rungan, ${ }^{1}$ Susan Woolfenden, ${ }^{1}$ Katrina Williams, ${ }^{2}$ \\ Lisa Woodland ${ }^{3}$
}

To cite: Zwi K, Rungan S, Woolfenden S, et al. Methods for a longitudinal cohort of refugee children in a regional community in Australia. BMJ Open 2016;6: e011387. doi:10.1136/ bmjopen-2016-011387

- Prepublication history for this paper is available online. To view these files please visit the journal online (http://dx.doi.org/10.1136/ bmjopen-2016-011387).

Received 3 February 2016 Revised 22 July 2016 Accepted 29 July 2016

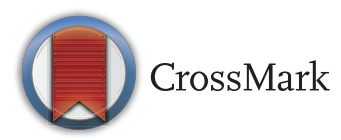

${ }^{1}$ Sydney Children's Hospitals Network and University of New South Wales, Sydney, New South Wales, Australia ${ }^{2}$ Royal Children's Hospital, Melbourne, Victoria, Australia ${ }^{3}$ District Executive Unit, South Eastern Sydney Local Health District, Sydney, New South Wales, Australia

Correspondence to Dr Karen Zwi;

karen.zwi@health.nsw.gov.au

\section{ABSTRACT}

Purpose: Few studies explore the long-term health and well-being of refugee children. A longitudinal cohort of refugee children was created to determine health and well-being outcomes over time. This article describes the methodology used to conduct this study, including sample characteristics and effectiveness of recruitment and retention strategies.

Participants: Newly arrived refugee children settling in a regional part of Australia aged 6 months to 15 years were recruited between 2009 and 2013 and $85 \%$ were followed for an average of 31 months.

Method and design: General practitioners conducted health and pathology examinations shortly after arrival. Additional follow-up assessments were conducted by the research team at an average of 13 months after arrival for the first (year 2) and 31 months for the second (year 3) assessment. Children under 5 years had developmental and children aged 4-17 years had social-emotional screening. Families were assessed for risk and protective factors using a structured interview and the Social Readjustment Ratings Scale. Parent experience of the research was explored.

Findings to date: Eligibility criteria were met by 158 of $228(69 \%)$ newly arrived children, 61 of whom $(39 \%)$ were enrolled. Retention was $100 \%$ ( $n=61)$ at year 2 and $85 \%$ at year 3 . The study sample was younger than and had an over-representation of African refugees as compared to the eligible population. Parents reported that the research was respectful.

Future plans: This study demonstrates that a longitudinal cohort study in refugee children is feasible and acceptable, and retention rates can be high. The establishment of this cohort provides the opportunity to analyse valuable data about the early settlement experience, risk and protective factors and long-term health and well-being outcomes in refugee children. These are necessary to identify refugee children in need of additional support and to guide future service delivery.

\section{INTRODUCTION}

Australia accepts around 13 000-20 000 refugees per year under the humanitarian programme, with $40-50 \%$ of these entrants

\section{Strengths and limitations of this study}

- The strength in the study design was recruitment through an established high-uptake populationbased screening programme for refugees and using trusted nurses to enrol families and provide ongoing care.

- The study demonstrated feasibility and acceptability in examining a wide range of risk and protective factors and measuring health and well-being outcomes over 2-3 years in a population known to be challenging to follow up.

- A key strength was the consideration of many important factors in conducting ethical research in this highly vulnerable population, creating the potential to add to the evidence base, gathering valuable data and contributing to policy and practice change.

- We sought to offset an important limitation, small sample size, by investing in retention strategies to minimise attrition, which were effective once participants were recruited.

- Limited availability of professional healthcare interpreters was a key challenge in recruitment and the need for interpreters also increased the length of assessment time and study costs.

being children and young people below 25 years. ${ }^{1}$ Children from a refugee background often arrive in Australia with unmet health, developmental and social-emotional needs due to a combination of factors including forced migration, suboptimal living conditions and limited access to healthcare. ${ }^{2}{ }^{3}$ Refugee children are particularly at risk of adverse developmental and mental health outcomes because of the refugee experience itself and the process of resettlement. ${ }^{4-6}$ Routine health screening on arrival is recommended by the Royal Australasian College of Physicians (RACP) and detects many significant and treatable health problems. However, the need for routine screening of developmental or social-emotional well-being in the period after resettlement has not been formally examined in cross-sectional or 
prospective studies due to challenges in conducting such studies in refugee populations. ${ }^{7-13}$

Prospective studies are advantageous in that they allow researchers to track individual children over time, thereby reducing recall bias associated with retrospective studies. They can gather information on risk and protective factors associated with key outcomes and thus identify children at higher risk of poor outcomes. ${ }^{14-16}$ The Australian National Health and Medical Research Council (NHMRC) provides recommendations for research in vulnerable communities, including that such research is descriptive in nature, longitudinal in design, collects evidence to effect change and is underpinned by an ethical theoretical framework that guides design and implementation to produce robust data on health and well-being. ${ }^{17-19}$

Research in refugee children presents multiple challenges, including (1) access to a suitable cohort; (2) language and cultural barriers; (3) lack of cross-cultural validation of standardised screening tools and (4) working with vulnerable children and families, including parental concerns about research participation. Furthermore, long-term follow-up and interpreter costs make such research expensive to undertake in an ethical manner. These challenges have led to systematic exclusion of refugee children from key longitudinal research studies in Australia. ${ }^{20} 21$ The Longitudinal Study of Australian Children (LSAC) does not include sufficient numbers of refugee children to allow identification of their specific needs, and the Longitudinal Survey of Immigrants to Australia (LSIA) focuses on adult immigrants as the primary participants. ${ }^{20}{ }^{21}$ Only one longitudinal study of refugee youth has been conducted in Australia and the outcome was limited to self-rated well-being. ${ }^{16}$

This article describes the methodology used to conduct a longitudinal cohort study of refugee children in a regional community in Australia, including sample characteristics, and the effectiveness of recruitment and retention strategies employed. The purpose of this cohort was to explore how refugee children are tracking over time, particularly in relation to their development and social-emotional well-being, and risk and protective factors associated with these outcomes.

\section{METHODS AND DESIGN}

\section{Setting}

The Illawarra region of New South Wales, Australia, has a long history of refugee resettlement including European communities following World War II, the Vietnamese community in the 1970s and the Serbian, Croatian and Bosnian communities in the 1990s. The most recent arrivals are from African countries, Burma and the Middle East. ${ }^{1}$ In this region, a collaborative GP-led communitybased model of care has been in place since 2007. This model operates through settlement services, which link new arrivals with a network of local refugee-friendly general practitioners (GPs), who provide initial health screening and ongoing family-centred care. Refugee Health Nurses (RHNs) provide support to GPs and ensure health needs are addressed. Specialist health services provide training forums, screening and management guidelines, access to rapid tertiary-level consultative expertise and specialised Refugee Health Clinics. This collaborative model of care has been shown to be successful in undertaking physical health screening of the entire population $(100 \%)$ of newly arrived refugee children settling in the region ${ }^{22}$ (K Zwi, N Morton, L Woodland, et al Screening and primary care access for newly-arrived paediatric refugees in regional Australia: a 5-year cross sectional analysis (2007-2012). J Tropical Pediatrics (Under Resubmission)). ${ }^{23}$

\section{Recruitment and participants}

Participants were recruited into the study through the existing model of care described and building on the established relationships with refugee communities and health professionals working with them. We recruited participants from eligible children who were aged 0-15 years, arrived in Australia on permanent humanitarian visas between May 2009 and April 2013 and settled within the regional catchment area of the Illawarra Shoalhaven Local Health District. A maximum of two children per family were eligible to reduce the respondent burden for the family. We preferentially recruited the youngest two children as they were more likely to be at home during school or working hours, and we were particularly interested in capturing as many young children as possible to assess child development.

Soon after arrival, RHNs approached families with information about the study seeking permission to contact over time, full written consent and permission to recruit for research purposes. If obtained, the family was contacted for follow-up assessments which occurred between April 2010-January 2014 (year 2 assessments) and March 2013-August 2014 (year 3 assessments).

The RHNs were chosen as the primary research assistants because they were respected and trusted by settlement services and community members. The RHNs also provided a safety net for this vulnerable population because they were skilled in referring children and families to the complex network of settlement and mainstream health services available. All interactions, apart from administrative telephone calls, were conducted with a face-to-face professional healthcare interpreter present (figure 1).

Given the importance of maintaining follow-up in this cohort, a number of strategies to minimise attrition were employed (box 1).

\section{Measurement instruments}

Key outcomes for the study were physical health, child development and social-emotional well-being (table 1). 


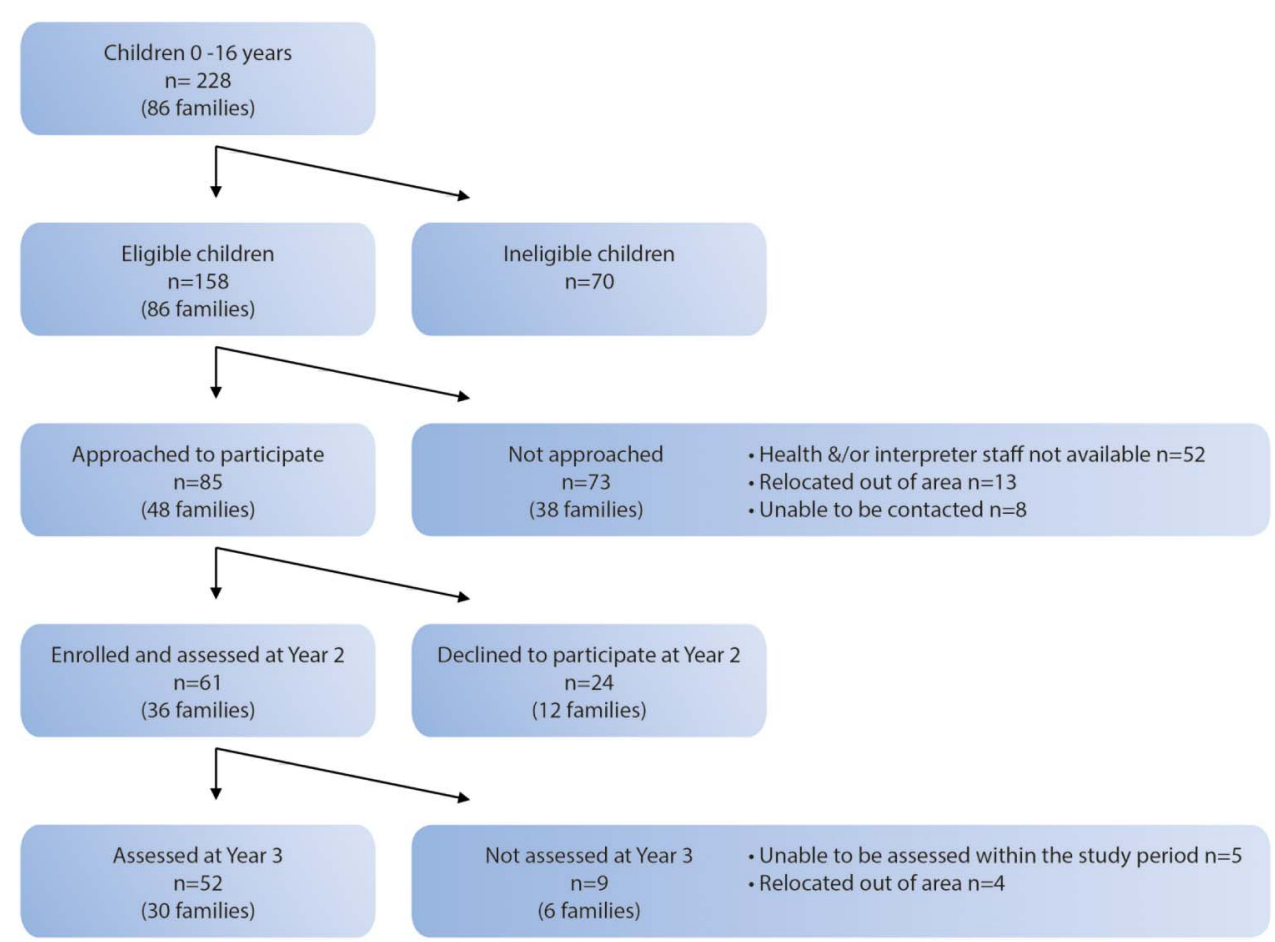

Figure 1 Recruitment and retention.

Box 1 Retention strategies to minimise attrition included

- Conducting a small pilot study to ensure that tools and questionnaires were acceptable to families;

- Ensuring phone calls and interviews were scheduled at convenient times for families;

- Conducting assessments in the participants' homes;

- Employing multiple call back strategies to make initial contact and to convert contact into a completed interview;

- Conducting interviews which engage and interest respondents;

- Providing feedback to parents about the outcomes of screening;

- Undertaking to organise further services as required as well as support to access appointments;

- Encouraging community support through regular feedback to local community organisations and settlement services, participation in community health promotion activities and written information;

- Working closely with GPs and settlement services who could provide updated contact details for families.

\section{Physical health assessment}

The initial clinical evaluation included a history and examination, screening tests and anthropometric measurements (height, weight and body mass index (BMI)). A schistosomiasis $\operatorname{IgG}$ ratio of $<0.7$ and a strongyloides IgG ratio of $<0.8$ were considered negative. Malaria screening comprised a thin smear, thick smear and a rapid diagnostic test. All children had tuberculosis screening using an interferon- $\gamma$ release assay, QuantiFERON TB Gold (QFN). Low ferritin levels $(<20 \mu \mathrm{g} / \mathrm{L})$ were used as a marker of iron deficiency.
Vitamin D levels were defined as sufficient (50-230 $\mathrm{nmol} / \mathrm{L})$, mild (26-50 nmol/L), moderate (12.5-25 $\mathrm{nmol} / \mathrm{L})$ and severe $(<12.5 \mathrm{nmol} / \mathrm{L})$ deficiency. ${ }^{8}$ Anthropometric measurements were repeated at years 2 and 3 .

\section{Development}

The Australian Developmental Screening Test (ADST) was selected to assess development in younger children because of its properties as a standardised, individually administered, objective and play-based developmental screening test. ${ }^{30}$ The tool assesses five domains of development (language, cognitive skills, fine motor skills, personal/social skills and gross motor skills) and was administered by the RHN playing with the child and requesting information from the parent over $\sim 30 \mathrm{~min}$. Using published modified diagnostic criteria, specificity and sensitivity of ADST scores correlate well with the gold standard Griffiths Mental Developmental Scales (GMDS). ${ }^{30}$ The ADST domains were scored to produce a developmental age in months and categorised into two possible outcomes: (1) normal and (2) monitor (for children requiring review over time but not necessarily intervention).

\section{Social-emotional well-being}

The parent-reported version of the Strengths and Difficulties Questionnaire (SDQ) was completed by parents to identify social-emotional problems in children and young people from 4 to 17 years of age. This tool was selected because it has been validated for use across cultures, is quick to administer and has demonstrated 
Table 1 Measurement of child outcome measures, by age group

\begin{tabular}{|c|c|c|c|}
\hline Outcome & Assessment & $\begin{array}{l}\text { Timing of } \\
\text { assessment }\end{array}$ & Rationale \\
\hline \multirow[t]{2}{*}{$\begin{array}{l}\text { Physical health (children } \\
\text { aged } 6 \text { months to } \\
17 \text { years) }\end{array}$} & $\begin{array}{l}\text { Pathology tests } \\
\text { Full blood count, renal and liver } \\
\text { function tests } \\
\text { Ferritin level } \\
\text { Vitamin D level } \\
\text { Serology for hepatitis B, hepatitis C, } \\
\text { HIV, syphilis, schistosomiasis, } \\
\text { strongyloides and immunity to } \\
\text { rubella, measles and mumps. } \\
\text { Malaria thin and thick smear, and a } \\
\text { rapid diagnostic test. } \\
\text { QFN }\end{array}$ & On arrival & $\begin{array}{l}\text { Child health is associated with health } \\
\text { in later life }\end{array}$ \\
\hline & Child's height, weight and BMI & $\begin{array}{l}\text { On arrival } \\
\text { Year } 2 \\
\text { Year } 3\end{array}$ & $\begin{array}{l}\text { Underweight is associated with poor } \\
\text { school performance. }{ }^{24} 25 \\
\text { Obesity is associated with several } \\
\text { health problems. }^{25}\end{array}$ \\
\hline $\begin{array}{l}\text { Development* (children } \\
\text { aged } 6 \text { months to } \\
5 \text { years) }\end{array}$ & $\begin{array}{l}\text { ADST } \\
\text { Personal/social } \\
\text { Language } \\
\text { Cognitive } \\
\text { - Fine motor } \\
\text { - Gross motor }\end{array}$ & $\begin{array}{l}\text { Year } 2 \\
\text { Year } 3\end{array}$ & $\begin{array}{l}\text { Child development associated with } \\
\text { school readiness, social development } \\
\text { and later academic achievement. }{ }^{26} 27\end{array}$ \\
\hline $\begin{array}{l}\text { Social-emotional } \\
\text { well-being (children aged } \\
4 \text { years to } 17 \text { years) }\end{array}$ & $\mathrm{SDQ}$ & $\begin{array}{l}\text { Year } 2 \\
\text { Year } 3\end{array}$ & $\begin{array}{l}\text { Social-emotional well-being } \\
\text { associated with positive health and } \\
\text { educational outcomes. }\end{array}$ \\
\hline
\end{tabular}

reasonable cross-informant correlations, good internal consistency and correlation with Rutter scales and the Achenbach Child Behaviour checklist. ${ }^{31-35}$ Translated SDQs were used if available (Arabic and Farsi), and the primary respondent was literate in their first language. Interpreters were briefed before assessments to ensure consistency between interpreters and translated SDQs.

The SDQ includes 25 items with 5 symptom scales to evaluate emotional symptoms, conduct problems, hyperactivity and inattention, peer relations and prosocial behaviour. ${ }^{36}$ Scores were generated for each subscale and the total difficulties. High SDQ scores indicate an increased risk of social-emotional problems. The SDQ scores were classified into three categories: (1) normal, (2) borderline and (3) abnormal. Children who scored in the abnormal or borderline ranges on the developmental or social-emotional screening assessments were referred to the local Refugee Child Health clinical team or their GP.

\section{Risk and protective factors}

Risk and protective factors for health outcomes were assessed using a structured interview (box 2) and the Holmes and Rahe Social Readjustment Rating Scale (SRRS). ${ }^{37} 38$ The SRRS was used to measure the impact of stressful life events occurring in the previous 12 months, such as changes in family composition,

\section{Box 2 The structured interview information includes}

- Need for and access to health services over the previous 3 months, including health problems/injuries experienced by the child; visits to the GP and other health professionals; presentations to the emergency department or hospital; immunisation or preventive health activities;

- Access to socio-economic resources (such as salaries, grants and pensions);

- Access to community support (such as neighbours, religious and/or community organisations);

- Family stressors and life events post arrival (including moving house or death of family members);

- Exposure to perceived racism or other forms of discrimination;

- Experience of the study questionnaire (whether it was easy to understand, respectful or produced any confusion or uncomfortable feelings).

employment and stability of residence. Scores that were $>150$ on the scale indicate a moderate to high risk (over $80 \%$ chance) of developing a stress-related illness. ${ }^{39} 40$ As part of the structured interview, parents were asked about their experience of participating in the research and whether the study questionnaire was easy to understand and respectful or produced any confusion or uncomfortable feelings. 
The underlying theoretical model for analysis of the cohort data is the bio-ecological model of child health. ${ }^{41}$ In keeping with this, risk and protective factors were classified into: (1) child factors (age, gender, physical health on arrival, presence of chronic disease and BMI), (2) family factors (family composition, parental disclosure of trauma, born in a refugee camp and region of origin) and (3) settlement factors (stressful life events in last year, employment and study status, English language proficiency, socio-economic resources, experience of discrimination and access to healthcare; table 2).

\section{Measurement schedule}

The measurement schedule was as follows: GPs conducted the physical health examinations and pathology testing on all children shortly after arrival (average 20.4 days; range 6-98 days), consistent with the model of care (within the first year; year 1 assessments). Research assessments were carried out by the research team, which included RHNs and paediatric doctors. The first follow-up assessment occurred at year 2 (average 13 months after arrival; range 6-23 months) and the second follow-up assessment occurred at year 3 (average 31 months after arrival; range 21-40 months). Developmental and social-emotional screening assessments were delayed until years 2 and 3 to allow for a period of adjustment and to reduce capturing immediate resettlement stress.

At years 2 and 3 , children aged 6 months to 5 years had developmental screening assessments using the ADST; children aged 4-17 years had social-emotional screening assessments using the SDQ. Children aged 4-5 years were eligible for screening assessments. ${ }^{36} 37$

Before finalising the measurement schedule, we conducted a small pilot study in three families. Based on these assessments and participant feedback, a few questions were altered, repetitive questions were removed and the measurement instruments were reduced in number to limit assessment at each time point to 8 hours, conducted over two sessions for each child.

\section{Data management}

An Access database was developed to capture the data for the study, including demographic, physical health, child development (ADST) and social-emotional health (SDQ) data and risk and protective factors (SRRS and structured interviews). Information was entered by RHNs.

\section{Data analysis}

All data were analysed by SPSS V.22.0 using a predetermined analysis plan (SPSS version 22.0. IBM, USA). Categorical data were described with frequency percentages. Continuous data were described with means and SDs, and effect sizes between groups were calculated as the mean difference divided by the pooled SD. ${ }^{42}$ The data from the structured interviews of parents' research experience was recorded categorically in Access, coded in SPSS and analysed using quantitative methods.

\section{FINDINGS TO DATE}

\section{Recruitment and retention}

In the 4-year period between May 2009 and April 2013, 86 refugee families arrived in the study region with a total number of 228 children aged 6 months to 15 years (figure 1). The eligibility criteria for the study were met by 158 children; the main reason for ineligibility was that two children per family had been enrolled. Of the 158 eligible, 85 (54\%) children were approached and 61 children were recruited for the study (27\% of all newly arrived children and $39 \%$ of all eligible children). The remaining 73 children were not approached for recruitment due to limited availability of interpreters for research purposes and part-time research staff $(n=52$; $71 \%)$, families relocating out of the area $(n=13 ; 18 \%)$ and inability to contact families $(n=8 ; 11 \%)$.

\begin{tabular}{|c|c|c|c|}
\hline & Risk and protective factors & Measurement instrument & Timing of assessment \\
\hline Child factors & $\begin{array}{l}\text { Age } \\
\text { - Gender } \\
\text { Physical health on arrival } \\
\text { Presence of chronic disease } \\
\text { - BMI }\end{array}$ & $\begin{array}{l}\text { Physical health assessment } \\
\text { - Structured questionnaire }\end{array}$ & $\begin{array}{l}\text { On arrival } \\
\text { Year } 2 \\
\text { Year } 3\end{array}$ \\
\hline Family factors & $\begin{array}{l}\text { Family composition } \\
\text { Parental disclosure of trauma } \\
\text { Born in a refugee camp } \\
\text { - Region of origin }\end{array}$ & $\begin{array}{l}\text { SRRS } \\
\text { Structured questionnaire }\end{array}$ & $\begin{array}{l}\text { Year } 2 \\
\text { Year } 3\end{array}$ \\
\hline Settlement factors & $\begin{array}{l}\text { Stressful life events in the last year } \\
\text { Employment and study status } \\
\text { English language proficiency } \\
\text { Socio-economic resources } \\
\text { Experience of discrimination } \\
\text { Access to healthcare }\end{array}$ & $\begin{array}{l}\text { SRRS } \\
\text { Structured questionnaire }\end{array}$ & $\begin{array}{l}\text { Year } 2 \\
\text { Year } 3\end{array}$ \\
\hline
\end{tabular}


The enrolled sample was similar to the eligible population in terms of gender, but the mean age (6 years; $\mathrm{SD}=4$ years) was younger than that of the eligible population (9 years; $\mathrm{SD}=4.5$ years; table 3 ), consistent with preferentially including the youngest two children in each family. The sample had similar proportions to the eligible population for the Eastern Mediterranean WHO region of origin (21\% vs $26 \%$, respectively), but the South East Asian region was over-represented $(43 \%$ vs $32 \%)$ and the African region was under-represented (33\% vs $42 \%)$. This reflected the availability of languagespecific interpreters available to facilitate recruitment during the study period.

Primary respondents of the structured interviews were predominantly mothers $(\mathrm{n}=32 ; 62 \%$; table 3$)$. All children $(100 \%)$ were assessed at year $2(n=61)$ between April 2010 and January 2014. At year 3, 52 children were assessed, which represented a retention rate of $85 \%$. Nine children could not have their year 3 assessment within the study time frame due to study delays, resource constraints or relocation out of the area. These children were similar to the study sample in terms of gender, age, WHO region of origin, language spoken at home, prior education and employment of the primary respondent.

\section{Participant experience}

The study was generally considered acceptable to parents. The majority found the questionnaires easy to answer (year 2: 33/39, 85\%; year 3: 35/42, 83\%) without being confusing (year 2: 28/39, $72 \%$; year 3 : $43 / 47,91 \%$ ) or raising uncomfortable feelings (year 2 : $37 / 37,100 \%$; year 3: 36/39, 92\%), and all parents found the research respectful.

\section{Management of the project}

The Research Implementation Committee managed the day-to-day operational aspects of the study and met monthly. A Project Management Committee with representatives from each of the partner organisations as well as policy and implementation agencies met quarterly for strategic oversight, reporting and feedback.

\section{DISCUSSION}

A growing body of research demonstrates that optimising development (including language and cognitive development, social-emotional and physical health) in early childhood has positive long-term benefits including increasing children's intelligence, school achievement, employment, mental health and socio-economic status in adulthood. ${ }^{24-29}$ Children from a refugee background are often exposed to significant levels of trauma and instability during the early years, which increase their risk of poor developmental and social-emotional health outcomes. ${ }^{43-48}$ The longitudinal cohort study described in this article was designed to use an existing high-uptake model of care to access the newly arrived refugee population to measure health, developmental and socio- emotional well-being outcomes and examine a wide range of risk and protective factors.

Research in refugee populations may present specific challenges, but studies such as this can ensure that services are evidence-based, target refugee-specific needs and produce optimal outcomes. Refugee participation in research is important as exclusion may create systems of care directed at the 'mainstream', limiting the ability of research to reduce inequities in health. ${ }^{49}{ }^{50}$ This prospective cohort study provides the methodology to achieve this end, but has faced a number of logistic difficulties. Recruitment was anticipated to be a challenge in establishing this cohort and was indeed low at $39 \%$ of eligible children. However, participant refusal was lower than expected and occurred in only $15 \%$ of newly arrived families.

A fundamental challenge in conducting this study was that professional healthcare interpreters were expensive and availability was limited, especially for some new and emerging language groups (eg, Amharic). The research team considered face-to-face interpreters essential to enable families to give informed consent and for ongoing participation. Understandably, interpreter services prioritised clinical consultations over research requests, which led to the lack of capacity to approach some families. The need for interpreters also increased the length of assessment time, affecting maintaining the child's attention. Furthermore, some emerging local refugee communities were so small that there were participant concerns regarding interpreter confidentiality.

This study was limited by small sample size, but we offset this by investing in effective retention strategies to minimise attrition. Attrition is more common in the early years of longitudinal studies and occurs for various reasons including relocation, time constraints or loss of interest. ${ }^{51}$ We expected amplification of this effect in the refugee population due to cultural and language barriers, or precipitated by the refugee experience, such as mistrust of researchers and concerns about the results affecting immigration status. In contrast, once participants were recruited, $100 \%$ remained engaged at year 2 and the majority $(85 \%)$ at year 3 . Retention was higher than in other local studies in vulnerable populations in which retention at $2^{1 / 2}$ to 3 years ranged from $62.5 \%$ in a home visiting trial in a disadvantaged urban community to $78 \%$ in a refugee youth study and an urban birth cohort of Aboriginal babies and their mothers. ${ }^{16}$ 51-59 The high retention in this study reflects the considerable effort made by the research team to retain the sample with specific retention strategies, particularly home visits, flexible timing of appointments and willingness of the research team to assist families with any challenges confronting them, including housing and education.

Measurement instrument selection is important, and unfortunately, developmental and social-emotional wellbeing screening tools have not been validated in refugee children. Children's scores on the developmental tool used in this study may require careful interpretation due 
Table 3 Demographic details of eligible population, study sample and respondent characteristics

\begin{tabular}{|c|c|c|c|c|}
\hline & \multicolumn{2}{|c|}{ Eligible children $(n=158)$} & \multicolumn{2}{|c|}{ Study sample $(n=61)$} \\
\hline & Number & Percentage & Number & Percentage \\
\hline \multicolumn{5}{|l|}{ Characteristics of child } \\
\hline \multicolumn{5}{|l|}{ Gender } \\
\hline Male & 78 & 49 & 29 & 48 \\
\hline Female & 80 & 51 & 32 & 52 \\
\hline Mean age on arrival (years) & 9 & & 6 & \\
\hline \multicolumn{5}{|l|}{ WHO region (County of origin) } \\
\hline African & 66 & 42 & 20 & 33 \\
\hline DR Congo & & & 12 & \\
\hline Ethiopia & & & 2 & \\
\hline Kenya & & & 2 & \\
\hline Malawi & & & 2 & \\
\hline Burundi & & & 1 & \\
\hline Togo & & & 1 & \\
\hline Eastern Mediterranean & 41 & 26 & 13 & 21 \\
\hline Iran & & & 5 & \\
\hline Iraq & & & 5 & \\
\hline Lebanon & & & 3 & \\
\hline Europe & 1 & $<1$ & 0 & 0 \\
\hline South East Asia & 50 & 32 & 28 & 46 \\
\hline Burma & & & 28 & \\
\hline \multicolumn{5}{|l|}{ Languages spoken at home } \\
\hline Amharic & & & 2 & 3 \\
\hline Arabic & & & 8 & 13 \\
\hline Burmese & & & 13 & 22 \\
\hline Chin Senthang & & & 2 & 3 \\
\hline English & & & 4 & 7 \\
\hline Farsi & & & 5 & 8 \\
\hline French & & & 2 & 3 \\
\hline Karen & & & 10 & 17 \\
\hline Karenni & & & 3 & 5 \\
\hline Kirundi & & & 3 & 5 \\
\hline Swahili & & & 8 & 13 \\
\hline \multicolumn{5}{|c|}{ Characteristics of primary respondent } \\
\hline \multicolumn{5}{|c|}{ Gender $(n=60)$} \\
\hline Male & & & 23 & 38 \\
\hline Female & & & 37 & 62 \\
\hline \multicolumn{5}{|l|}{ Prior education $(n=54)$} \\
\hline None & & & 4 & 7 \\
\hline Primary & & & 15 & 27 \\
\hline Secondary & & & 23 & 43 \\
\hline University & & & 9 & 17 \\
\hline Trade & & & 3 & 6 \\
\hline \multicolumn{5}{|c|}{ Employment in home country $(n=53)$} \\
\hline Professional & & & 17 & 32 \\
\hline Semiskilled/unskilled & & & 19 & 36 \\
\hline Voluntary & & & 5 & 9 \\
\hline Unemployed & & & 12 & 23 \\
\hline \multirow{2}{*}{\multicolumn{5}{|c|}{$\begin{array}{l}\text { Characteristics of partner of primary respondent } \\
\text { Gender }(n=41)\end{array}$}} \\
\hline & & & & \\
\hline Male & & & 18 & 44 \\
\hline Female & & & 23 & 56 \\
\hline \multicolumn{5}{|l|}{ Prior education $(n=34)$} \\
\hline None & & & 1 & 3 \\
\hline Primary & & & 11 & 32 \\
\hline Secondary & & & 16 & 47 \\
\hline University & & & 6 & 18 \\
\hline Trade & & & 0 & 0 \\
\hline
\end{tabular}


Table 3 Continued

\begin{tabular}{|c|c|c|c|c|}
\hline & \multicolumn{2}{|c|}{ Eligible children $(n=158)$} & \multicolumn{2}{|c|}{ Study sample $(n=61)$} \\
\hline & Number & Percentage & Number & Percentage \\
\hline \multicolumn{5}{|c|}{ Employment in home country $(n=34)$} \\
\hline Professional & & & 11 & 32 \\
\hline Semiskilled/unskilled & & & 16 & 47 \\
\hline Voluntary & & & 3 & 9 \\
\hline Unemployed & & & 4 & 12 \\
\hline
\end{tabular}

to the presentation of unfamiliar images used in the testing kit and children's past exposure to play, literacy and numeracy materials (such as writing their name and address, threading beads, knowing colours and using scissors). Cultural and family practices also influence the usefulness of standardised tests. Nonetheless, it is almost impossible to develop 'culture-free' cognitive tools and there is a value in having generally applicable expectations and standards for children's development. ${ }^{54-57}$

Any assessment is vulnerable to intrinsic error such as wanting to please the researcher. This may be amplified in the refugee setting as parents may view the child's performance as a reflection of their family and community and fear impact of the child's results on their immigration status. This was the explicit reason for conducting developmental screening assessments using mostly researcher observed, play-based rather than parent-reported skills.

This research is an example of 'action research' where researchers, parents, service delivery agencies and government policy and implementation sectors work together to improve refugee child health. ${ }^{58} 59$ The interconnectedness with local resources and infrastructure, rather than a separate vertical research-funded suite of interventions, makes the implementation of future recommendations more likely to be sustainable.

The use of clinician refugee nurses as researchers may present a tension between having objective research staff at arm's length from clinical care, with 'blinded' researchers completing follow-up assessments to minimise bias, as compared with researcher-clinicians embedded in existing service systems to maximise recruitment. While the latter may affect the 'purity' of an observational longitudinal study, it allows for ethical research in communities in whom researchers would otherwise be passively observing and documenting unmet health needs. Participants are more likely to access care that the research identifies they require, as well as to remain engaged in the research, if there are close researchclinical linkages. ${ }^{60}$ Clinician-researchers can also serve as effective 'bridges' between the research and practice communities and can facilitate the development of clinically relevant research and the dissemination of evidence-based practice into routine clinical services. ${ }^{61}$ It is important when using the researcher-clinician model that there is no inadvertent coercion to participate due to the close linkage between clinical care and research. ${ }^{17-19} 5061$

\section{Future plans}

This longitudinal cohort study is the first of its kind in a refugee child population and demonstrates feasibility and acceptability to families of the measures employed. The establishment of this cohort provides the opportunity for the research team to gather valuable data about the early settlement experience, risk and protective factors and long-term health, developmental and socialemotional well-being outcomes in refugee children. Further funding is being sought to continue follow-up with the existing cohort of refugee children and to increase the sample size by including other jurisdictions.

The next phase will be to investigate how these risk and protective factors are related to health and wellbeing outcomes in refugee children. The involvement of key service providers and policymakers in this study aims to ensure optimal translation of findings to policy and service development. This is vital so that refugee children at risk of adverse health and well-being outcomes are identified early after arrival and can access the interventions they require.

Acknowledgements The authors acknowledge participating families and children, Refugee Health Nurses Jenny Lane, Colleen Allen and Lisa Atkins, paediatric fellows Janka Paprckova, Meredith Sissons and Marion Mateos, Statistician Jenny Peat and medical student Zita Halvert-Bruce.

Contributors KZ conceived of the study, and provided leadership in its design and coordination, conceptualised the analysis and drafted the manuscript. SR performed statistical analysis and helped draft the manuscript. SW participated in the study design and reviewed the manuscript. KW participated in the study design and reviewed the manuscript. LW participated in study design and coordination, performed statistical analysis and reviewed the manuscript. All authors read and approved the final manuscript.

Funding This study was funded by Foundation Markets Foundation for Children to the value of AUD\$158 000 over July 2009-June 2011.

Competing interests None declared.

Patient consent Obtained.

Ethics approval Human Research Ethics Committee Northern Hospitals Network, South Eastern Sydney Illawarra Area Health Service (HREC Ref No 09/163).

Provenance and peer review Not commissioned; externally peer reviewed.

Data sharing statement Since this article describes the establishment of a longitudinal cohort and early findings, full results will be submitted for peer-reviewed publication in due course. The authors are willing to share unpublished data with interested parties.

Open Access This is an Open Access article distributed in accordance with the Creative Commons Attribution Non Commercial (CC BY-NC 4.0) license, which permits others to distribute, remix, adapt, build upon this work 
non-commercially, and license their derivative works on different terms, provided the original work is properly cited and the use is non-commercial. See: http://creativecommons.org/licenses/by-nc/4.0/

\section{REFERENCES}

1. DIAC. Department of immigration and citizenship settlement database. http://www.immi.gov.au/refugee/index.htm (accessed Jun 2016).

2. Davidson N, Skull S, Burgner D, et al. An issue of access: delivering equitable health care for newly arrived refugee children in Australia. $J$ Paediatr Child Health 2004;40:569-75.

3. Raman S, Wood N, Webber M, et al. Matching health needs of refugee children with services: how big is the gap? Aust $N Z J$ Public Health 2009;33:466-70.

4. Ehntholt KW. Practitioner review: assessment and treatment of refugee children and adolescents who have experienced war-related trauma. J Child Psychol Psychiatry 2006;47:1197-210.

5. Australian Human Rights Commission Report. The Forgotten Children: National Inquiry into Children in Immigration Detention 2014 Australian Human Rights Commission 2015, Sydney, Australia. https://www.humanrights.gov.au/our-work/asylum-seekers-andrefugees/projects/national-inquiry-children-immigration-detention-index (accessed Jun 2016)

6. Mutch $\mathrm{RC}$, Cherian $\mathrm{S}$, Nemba $\mathrm{K}$, et al. Tertiary paediatric refugee health clinic in Western Australia: analysis of the first 1026 children. $J$ Paediatr Child Health 2012;48:582-7.

7. Chaves NJ, Paxton G, Biggs BA, et al, on behalf of the Australasian Society for Infectious Diseases and Refugee Health Network of Australia Guidelines writing group. Recommendations for comprehensive post-arrival health assessment for people from refugee-like backgrounds. Surry Hills, NSW: Australasian Society for Infectious Diseases, 2016. First edition 2009. Second edition 2016 NSW (AU); ASID; 2016 (cited 16 June 2016). https://www.asid.net au/documents/item/1225 (accessed Jul 2016).

8. Paxton GA, Teale GR, Nowson CA, et al. Vitamin D and health in pregnancy, infants, children and adolescents in Australia and New Zealand: a position statement. Med J Aust 2013;198:142.

9. Davidson N, Skull S, Chaney G, et al. Comprehensive health assessment for newly arrived refugee children in Australia. J Paediatr Child Health 2004:40:562-8.

10. Sheikh M, Wang S, Pal A, et al. Vitamin D deficiency in refugee children from conflict zones. J Immigr Minor Health 2011;13:87-93.

11. Martin JA, Mak DB. Changing faces: a review of infectious disease screening of refugees by the migrant health unit, Western Australia in 2003 and 2004. Med J Aust 2006;185:607-10.

12. Zwi K, Paxton G, Cherian S, et al. Summary of position statement on refugee and asylum-seeker health. J Paediatr Child Health 2015;51:657.

13. Paxton GA, Cherian S, Zwi KJ. The Royal Australasian College of Physicians Position Statement on refugee and asylum seeker health. Med J Austr 2015;203:176-7.

14. Boyd A, Golding J, Macleod J, et al. Cohort profile: the 'Children of the 90s'-the index offspring of the Avon longitudinal study of parents and children. Int J Epidemiol 2013;42:111-27. doi:10.1093/ ije/dys064

15. Sanson A, Nicholson J, Ungerer J, et al. LSAC Discussion Paper No. 1. Introducing the Longitudinal Study of Australian Children. C Australian Institute of Family Studies-Commonwealth of Australia 2002. ISBN 064239496 2; ISSN 1447-1558 (Print); ISSN 14471566 (Online). http://www.growingupinaustralia.gov.au/pubs/ discussion/dp1/\#ch2 (accessed Jun 2016).

16. Correa-Velez I, Gifford SM, Barnett AG. Longing to belong: social inclusion and wellbeing among youth with refugee backgrounds in the first three years in Melbourne, Australia. Soc Sci Med 2010;71:1399-408

17. National Health and Medical Research Council (NHMRC). The NHMRC Roadmap: a strategic framework for improving Aboriginal and Torres Islander Health through research. Canberra, ACT: Commonwealth of Australia, 2002.

18. National Health and Medical Research Council (NHMRC) 2010. The NHMRC Road Map II: a strategic framework for improving the health of Aboriginal and Torres Strait Islander people through research. Canberra, ACT: Commonwealth of Australia, 2010. https://www. nhmrc.gov.au/_files_nhmrc/publications/attachments/r47.pdf (accessed Jun 2016).

19. National Health and Medical Research Council (NHMRC). Challenging ethical issues in contemporary research on human beings. Canberra, ACT: Australian Government, 2007. ISBN Print: 1864962933. https://www.nhmrc.gov.au/_files_nhmrc/publications/ attachments/e73_challenging_ethical_issues_contemporary_ research human beings.pdf (accessed Jun 2016).

20. Australian Institute of Family Studies. Longitudinal study of Australian children (LSAC). http://www.growingupinaustralia.gov.au/ pubs/asr/2014/asr2014a.pdf (accessed Jun 2016)

21. Australian Government. Department of Immigration and Citizenship. The longitudinal survey of immigrants to Australia. http://www.immi. gov.au/media/research/lsia/ (accessed Jun 2016).

22. Zwi K, Morton N, Woodland L, et al. Screening and primary care access for newly-arrived paediatric refugees in regional Australia: a 5-year cross sectional analysis (2007-2012). J Tropical Pediatrics (In press).

23. Woodland L, Burgner D, Paxton G, et al. Health service delivery for newly arrived refugee children: a framework for good practice. $J$ Paediatr Child Health 2010;46:560-7.

24. Wilkins AJ, O'Callaghan MJ, Najman JM, et al. Early childhood factors influencing health-related quality of life in adolescents at 13 years. J Paediatr Child Health 2004;40:102-9.

25. Tamayo T, Christian H, Rathmann W. Impact of early psychosocial factors (childhood socioeconomic factors and adversities) on future risk of type 2 diabetes, metabolic disturbances and obesity: a systematic review. BMC Public Health 2010;10:525.

26. Hertzman C, Siddiqi A, Hertzman E, et al. Bucking the inequality gradient through early child development. BMJ 2010;340:c468.

27. Thompson RA. Stress and child development. Future Child 2014;24:41-59.

28. Wachs TD, Georgieff M, Cusick S, et al. Issues in the timing of integrated early interventions: contributions from nutrition, neuroscience, and social-emotional research. Ann N Y Acad Sci 2014;1308:89-106.

29. Oberklaid F, Baird G, Blair M, et al. Children's health and development: approaches to early identification and intervention. Arch Dis Child 2013;98:1008-11.

30. Morris J, Perkins D, Sarkozy V, et al. Performance of the Australian developmental screening test in a clinical setting. J Paediatr Child Health 2012;48:1004-9.

31. Stone LL, Otten R, Engels RCME, et al. Psychometric properties of the parent and teacher versions of the Strengths and Difficulties Questionnaire for 4- to 12-year-olds: a review. Clin Child Family Psychol Rev 2010;13:254-74.

32. Theunissen MHC, Vogels AGC, de Wolff MS, et al. Characteristics of the strengths and difficulties questionnaire in preschool children. Pediatrics 2013;131:e446-54.

33. Woerner W, Fleitlich-Bilyk B, Martinussen R, et al. The strengths and difficulties questionnaire overseas: evaluations and applications of the SDQ beyond Europe. Eur Child Adolesc Psychiatry 2004;13 (Suppl 2):I147-54

34. Goodman R, Scott S. Comparing the Strengths and Difficulties questionnaire and the child behavior checklist: is small beautiful? J Abnorm Child Psychol 1999;27:17-24.

35. Ziaian $\mathrm{T}$, de Anstiss $\mathrm{H}$, Antoniou G, et al. Depressive symptomatology and service utilisation among refugee children and adolescents living in South Australia. Child Adolesc Ment Health 2012;17:146-52.

36. Coombs T. Australian mental health outcomes and classification network. Strengths and difficulties questionnaire training manual. 1st edn. Parramatta: NSW Institute of Psychiatry, 2005.

37. Burdon B. Australian developmental screening test: ADST. Australia: Harcourt Brace \& Co Group (Australia) Pty and the Social-emotional Corporation, 1993

38. Holmes $\mathrm{TH}$, Rahe $\mathrm{RH}$. The social readjustment rating scale. J Psychosom Res. 1967;11:213-8.

39. Rahe RH, Meyer M, Smith M, et al. Social stress and illness onset J Psychosom Res 1964;8:35-44.

40. Rahe RH, Mahan JL, Arthur RJ. Prediction of near-future health change from subjects' preceding life changes. J Psychosom Res 1970;14:401-6.

41. Bronfenbrenner U, Morris PA. The bioecological model of human development. In: Damon W, Lerner RM, eds. Handbook of child psychology: Vol. 1. Theoretical models of human development. Hoboken, NJ: John Wiley \& Sons, 2006:793-828.

42. Cohen J. Statistical power analysis for the behavioural sciences. 2nd edn. Hillsdale, NJ: Lawrence Eribaum Associates, 1988.

43. Bronstein I, Montgomery P. Psychological distress in refugee children: systematic review. Clin Child Fam Psychol Rev 2011;14:44-56.

44. Guruge S, Butt $H$. A scoping review of mental health issues and concerns among immigrant and refugee youth in Canada: looking back, moving forward. Can J Public Health 2015;106:e72-8.

45. Fazel M, Wheeler J, Danesh J. Prevalence of serious mental disorder in 7000 refugees resettled in Western countries: a systematic review. The Lancet 2005;365:1309-14. 
46. Meyer S, Murray LK, Puffer ES, et al. The nature and impact of chronic stressors on refugee children in Ban Mai Nai Soi camp, Thailand. Glob Public Health 2013;8:1027-47.

47. Leavey G, Hollins K, King M, et al. Social-emotional disorder amongst refugee and migrant schoolchildren in London. Soc Psychiatry Psychiatr Epidemiol 2004;39:191-5.

48. Bean T, Derluyn I, Eurelings-Bontekoe E, et al. Comparing socialemotional distress, traumatic stress reactions, and experiences of unaccompanied refugee minors with experiences of adolescents accompanied by parents. J Nerv Ment Dis 2007;195:288-97.

49. Jacobsen TN, Nohr EA, Frydenberg M. Selection by socioeconomic factors into the Danish National Birth Cohort. Eur J Epidemiol 2010;25:349-55

50. Woolfenden S, Eapen V, Axelsson E, et al, 'Watch Me Grow' study group. Who is our cohort: recruitment, representativeness, baseline risk and retention in the 'Watch Me Grow' study? BMC Pediatr 2016;16:46.

51. Kemp L, Harris E, McMahon C, et al. Miller Early Childhood Sustained Home-visiting (MECSH) trial: design, method and sample description. BMC Public Health 2008;29:424.

52. Comino E, Craig P, Harris E, et al. The Gudaga Study: establishing an Aboriginal birth cohort in an urban community. Aust N Z J Public Health 2010;34(Suppl 1):S9-17.

53. McDonald J, Webster V, Knight J, et al. The Gudaga Study: development in 3-year-old urban Aboriginal children. $J$ Paediatr Child Health 2014;50:100-6.
54. Bornstein MH, Cote LR. Mothers' parenting cognitions in cultures of origin, acculturating cultures and cultures of destination. Child Dev 2004;74:221-35.

55. Fox PG, Burns KR, Popovich JM, et al. Southeast Asian refugee children: self-esteem as a predictor of depression and scholastic achievement in the US. Int J Psychiatr Nurs Res 2004:9:1063-72.

56. Gokiert RJ, Chow W, Parsa B, et al. Early childhood screening in immigrant and refugee populations. Edmonton, Alberta, Canada: Community-University Partnership for the Study of Children, Youth, and Families, 2010.

57. Fernald LC, Kariger $\mathrm{P}$, Engle $\mathrm{P}$, et al. Examining early child development in low-income countries. Washington DC: The World Bank, 2009.

58. Robertsona J. The three Rs of action research methodology: reciprocity, reflexivity and reflection-on-reality. Educ Action Res 2000;8:307-26

59. Betancourt TS, Frounfelker R, Mishra T, et al. Addressing health disparities in the mental health of refugee children and adolescents through community-based participatory research: a study in 2 communities. Am J Public Health 2015;105(Suppl 3):e1-8.

60. Philip T, Yanos DM, Ziedonis MP. The patient-oriented clinicianresearcher: advantages and challenges of being a double agent. Psychiatr Serv 2006;57:249-53.

61. Brunero SJ, Jeon YH, Foster K. The journey of positioning self as both mental health nurse and qualitative researcher: a critical reflection. J Psychiatr Ment Health Nurs 2015;22:543-8. 